\title{
Lipid composition and DPPH activities of the seed oil of five Turkish hazelnut genotypes (Corylus colurna
} L.)

\author{
Jelena Ninić-Todorović ${ }^{1}$, Miroslav Novaković ${ }^{2}$, Jelena Čukanovićc ${ }^{1}$, IVAna Sofrenić ${ }^{3}$, \\ IVAN TOdorović ${ }^{4}$, Dragan TOdorović ${ }^{4}$, AND VELE TEŠEVIĆ ${ }^{3, *}$ \\ ${ }^{1}$ University of Novi Sad, Faculty of Agriculture, Trg Dositeja Obradovića 8, 21000 Novi Sad, Serbia \\ ${ }^{2}$ University of Belgrade, Institute of Chemistry, Technology and Metallurgy, Center for Chemistry, Njegoševa 12, 11000 Belgrade, Serbia \\ ${ }^{3}$ University of Belgrade, Faculty of Chemistry, Studentski trg 16, 11000 Belgrade, Serbia \\ ${ }^{4}$ University of Novi Sad, Faculty of Technical Sciences, Trg Dositeja Obradovića 6, 21000 Novi Sad, Serbia \\ *Corresponding author: vtesevic@chem.bg.ac.rs
}

Received: January 22, 2019

Accepted: April 25, 2019

Published on-line: November 15, 2019

Published: December 25, 2019

\begin{abstract}
Five genotypes of Turkish hazelnuts (Corylus colurna L.) were analyzed for chemical composition, including total oil content, fatty acid and sterol composition. The oil yields from these kernels varied from $36.5 \%$ to $60.8 \%$ and the main fatty acids were oleic acid (79.34-83.0\%) and linoleic acid (7.52-10.81\%). The polyunsaturated/saturated fatty acid ratio was low, ranging from 0.87 to 1.25 . Total phytosterol content ranged from 4.52 to $6.50 \mathrm{mg} \mathrm{g}^{-1}$ of oil. Among the eleven sterols identified and quantified, $\beta$-sitosterol was the major one with a mean percentage of $65.09 \%$ while fucosterol and campesterol were the second and the third components of the group with mean values of $10.91 \%$ and $4.36 \%$, respectively. The radical scavenging activity was evaluated using 2.2 -diphenyl-1 picrylhydrazyl (DPPH) assay.
\end{abstract}

Key words: Turkish hazel; oil content; fatty acids; sterols

\section{INTRODUCTION}

Genus Corylus is part of the Betulaceae family. It contains about 15 species of shrubs and trees that are native to the northern temperate regions of Europe, Asia, and North America. Commonly known as hazels, most of these plants feature clusters of yellow flowers and edible nuts. The commercial hazelnut, one of the world's major tree nut crops, is the European hazelnut (C. avellana L.). C. colurna, commonly known as the Turkish hazel, is native to southeast Europe and southwest Asia, through to the Balkans, Northern Turkey and Northern Iran (Thompson et al., 1996).

Due to their organoleptic characteristics, hazelnuts are consumed all over the world, not only as a fruit but also in a diversity of manufactured food products, such as snacks, chocolates, cereals, bakery, dairy, salad, entree, sauce, ice creams, and other dessert formulations (Ozdemir and Akinci, 2004; Amaral et al., 2006; Oliveira et al., 2008). Although Turkish tree hazelnuts are consumed, there are limited reports about their chemical composition. In a recent study, Erdogan and Aygun (2005) reported that the content of oil obtained from nuts of some Turkish tree hazel types ranged between $64.48 \%$ and $71.92 \%$. Oleic and linoleic acids were the pre- dominant fatty acids, together representing $91.70 \%$ of the total. The amount of palmitic and stearic acids was low while palmitoleic, margaric, margaroleic, linolenic, arachidic, and gadoleic acids were present in trace amounts. Similar oil content $(48.60-69.90 \%)$ and fatty acid composition was reported from Serbian samples of C. colurna nuts (Miletić et al., 2007; Ninić-Todorović, 1990).

The chemical composition of European hazelnuts has been the subject of numerous investigations. Examination of 24 hazel cultivars from Italy and other climates revealed that the fruit quality depends on the interaction between the genotype and environmental conditions (Cristofori et al., 2008). The authors found that high content of palmitic acid is present in the dry period. Also, the fatty acid content analysis was performed on Nebraska hybrid hazel nuts by Xu and Hanna (2010). Their findings indicated that oleic and linoleic acids were most abundant, contributing by over $90 \%$ to the total fatty acid content.

Fruit analysis of three hazel genotypes sourced from natural populations reveal presence of 16 fatty acids (Seyhan et al., 2007). The authors found no differences in the saturated fatty acid content at various stages of fruit maturity. Similarly, the samples of $C$. avellana oil contained the highest proportion 
of monounsaturated fatty acids (up to $79.5 \%$ ), followed by polyunsaturated fatty acids $(12.6 \%)$ and saturated fatty acids $(8 \%)$ (Parcerisa et al., 1998). In the resent study, Alasalvar et al. (2006) indicated that, in the hazelnut oil, oleic acid was the most common fatty acid with $82.78 \%$, followed by linoleic $(8.85 \%)$, palmitic $(4.81 \%)$ and stearic acid $(2.69 \%)$.

After analyzing the composition of authentic hazelnut oils obtained from nuts collected from five countries, Crews et al. (2005) found that the oleic acid content varied between 75.3 and $83.8 \%$, linoleic was in the $6.2-15.9 \%$ range, palmitic ranged from 5.0 to $6.6 \%$ and stearic varied between 1.6 to $2.9 \%$. Owing to the high oil content, hazel kernels could be used as raw material in biodiesel production (Xu and Hanna, 2009). Three decades ago, the Turkish hazel genotype selection program, using natural populations and trees of secondary origin, started in Serbia. The selection included the Turkish hazel population in the Danube Park, Futoški Park and the plant nursery in Novi Sad, from which 45 specimens were chosen. Although lipid characteristics of the Turkish hazelnut have been reported (Erdogan and Aygun, 2005; Miletić et al., 2007), there is no information on phytosterol compositions of hazelnut oil extracted from the Turkish hazelnut.

The aim of this study was to determine the oil content as well as the fatty acid and sterol composition of seeds from five Turkish hazelnut genotypes, to evaluate their potential for nutritional and medicinal applications.

\section{MATERIALS AND METHODS}

\subsection{Plant material collection}

During August 2016, seeds from five Turkish hazel genotypes were collected from a plant nursery in Novi Sad. Kernels of these genotypes were labelled as A8, A9, A11, B6 and B10, and sown in October in the Faculty of Agriculture plant nursery located in Rimski Šančevi, near Novi Sad.

\subsection{Oil content}

The oil contents of hazelnuts were determined according to AACC (1991). The nuts from different genotypes were first grounded separately and dried thoroughly in oven at $105^{\circ} \mathrm{C}$. The dried ground samples (approximately $3 \mathrm{~g}$ ) were placed in a thimble and the oil was extracted using $50 \mathrm{~mL}$ of $n$-hexane in a Soxhlet extractor for $8 \mathrm{~h}$. After the extraction, the $n$-hexane was evaporated and the collection cups containing the extracted oil were placed in a vacuum oven at $95{ }^{\circ} \mathrm{C}$ for $1 \mathrm{~h}$ in order to remove all traces of hexane. The oil content was expressed as the following:

$$
\% \text { oil content }=\frac{\text { weight of oil }}{\text { weight of sample }} \times 100
$$

\subsection{Chemical analysis of methyl esters}

Fatty acid methyl esters were prepared following IUPAC methodology without heating (IUPAC, 1987). A $100 \mathrm{mg}$ of raw seed oil was accurately weighed into a $20 \mathrm{~mL}$ centrifuge tube and dissolved in $5 \mathrm{~mL} n$-hexane. Then $0.2 \mathrm{~mL}$ of $2 \mathrm{M}$ solution of $\mathrm{KOH}$ in methanol was added. The tube was sealed and mixed vigorously for $30 \mathrm{~s}$ in a vortex shaker. Saturated $\mathrm{NaCl}$ solution $(2.0 \mathrm{~mL})$ was added and the organic phase was separated. The resulting methyl esters of fatty acids were analyzed by GC and GC-MS analysis.

The GC and GC-MS analyses were performed on an Agilent 7890A GC system equipped with 5975C inert XL EI/CI MSD and a FID detector connected by capillary flow technology 2way splitter with make-up gas. A DB-23 capillary column (60 $\mathrm{m} \times 0.25 \mathrm{~mm} \times 0.25 \mu \mathrm{m})$ was used. Samples were injected in split mode (30:1). The injection volume was $1 \mu \mathrm{L}$ and the injector temperature was $220^{\circ} \mathrm{C}$. The carrier gas (He) flow rate was
$3.3 \mathrm{~mL} / \mathrm{min}$ at $60{ }^{\circ} \mathrm{C}$ (constant pressure mode). The column temperature was initially set at $50{ }^{\circ} \mathrm{C}(1 \mathrm{~min})$, after which it was programmed to increment linearly in the $50-175^{\circ} \mathrm{C}$ range $\left(25^{\circ} \mathrm{C} / \mathrm{min}\right)$ and $175-235^{\circ} \mathrm{C}\left(4^{\circ} \mathrm{C} / \mathrm{min}\right)$, with final 5-min hold. The transfer line was heated at $235^{\circ} \mathrm{C}$. The FID detector temperature was $300^{\circ} \mathrm{C}$. EI mass spectra $(70 \mathrm{eV})$ were obtained in $\mathrm{m} / \mathrm{z}$ range of 35-550 atomic mass units (AMU), with $3 \mathrm{~min}$ solvent delay. The ion source and quadrupole temperatures were $230{ }^{\circ} \mathrm{C}$ and $150{ }^{\circ} \mathrm{C}$, respectively. Retention times of the fatty acid components of seeds were compared with the corresponding original fatty acids from GC, and mass spectra of individual components were identified by comparison with Wiley 07 and NIST 05 databases.

\subsection{Chemical analysis of unsaponifiables}

Sterols were determined by GC-MS of the complete unsaponifiable fraction. Internal standard solution of $10.0 \mathrm{mg}$ of cholesterol in methylene chloride $(0.1 \%)$ was added to 2.3 $\mathrm{g}$ of oil sample and the methylene chloride was evaporated. Prepared sample was saponified with $10 \mathrm{~mL}$ of $6 \mathrm{M}$ solution of $\mathrm{KOH}$ in water and $15 \mathrm{~mL}$ of EtOH (ethanol with up to $5 \%$ diethyl ether). The solution was refluxed for $90 \mathrm{~min}$ at $70{ }^{\circ} \mathrm{C}$ (water bath at $85-90^{\circ} \mathrm{C}$ ).

Following saponification, $15 \mathrm{~mL}$ of water was added and nonsaponifiable compounds were extracted, first with $22.5 \mathrm{~mL}$ of petroleum ether, and then with $22.5 \mathrm{~mL}$ of diethyl ether. The two extracts were combined and washed twice with 20 $\mathrm{mL}$ of $0.5 \mathrm{M}$ solution of $\mathrm{KOH}$ in water and with $20 \mathrm{~mL}$ of $5 \%$ $\mathrm{NaCl}$ solution in water until the $\mathrm{pH}$ of the washing water was neutral.

The organic fraction was dried with anhydrous $\mathrm{Na}_{2} \mathrm{SO}_{4}$ and filtrated over folded filter paper into a conical flask. The residue obtained after evaporation was derivatized by adding $1.5 \mathrm{~mL}$ of dry pyridine as solvent, $0.2 \mathrm{~mL}$ hexamethyldisilazane and $0.1 \mathrm{~mL}$ trimethylsilane as silylation agents. The flask was placed in an oven at $70{ }^{\circ} \mathrm{C}$ for $30 \mathrm{~min}$ for completion of the silylation. The derivatized sample was transferred into a vial and was ready for GC analysis. All samples were analyzed within 6 hours after derivatization. GC and GC-MS analysis were performed on same instrument (Agilent 7890A GC). An HP-5MS capillary column $(30 \mathrm{~m} \times 0.25 \mathrm{~mm} \times 0.25 \mu \mathrm{m})$ was used. The GC oven temperature was programmed to increase from $60{ }^{\circ} \mathrm{C}$ to $300{ }^{\circ} \mathrm{C}$ with $3{ }^{\circ} \mathrm{C} / \mathrm{min}$ increments, each held for $10 \mathrm{~min}$. The carrier gas $(\mathrm{He})$ flow rate was $3.3 \mathrm{~mL} / \mathrm{min}$ at 60 ${ }^{\circ} \mathrm{C}$ (constant pressure mode). The sample was analyzed in the splitless mode. The injection volume was $1 \mu \mathrm{L}, \mathrm{GC}$ detector temperature was $300{ }^{\circ} \mathrm{C}$. MS data was acquired in EI mode, with scan range $30-550 \mathrm{~m} / z$, source temperature of $230{ }^{\circ} \mathrm{C}$ and quadrupole temperature of $150{ }^{\circ} \mathrm{C}$. Solvent delay was set at $13 \mathrm{~min}$. Identification was confirmed by retention time lock (RTL) method and Wiley 07 and NIST 05 databases.

\subsection{DPPH radical scavenging activity}

The antioxidant activity of toluene solutions of the seed oils were tested against DPPH radicals using method described by Ramadan and Moersel (2006). Briefly, a volume of $1600 \mu \mathrm{L}$ of $0.1 \mathrm{mM}$ DPPH solution prepared also in toluene was added to $400 \mu \mathrm{L}$ of the toluene solutions of the oils in concentrations of $0.1,1.0,10$, and $100 \mu \mathrm{g} / \mathrm{mL}$, vortexed for $10 \mathrm{~s}$ and left in the dark for $1 \mathrm{~h}$ at room temperature. Absorbance of the samples at $515 \mathrm{~nm}$ was then recorded using a CINTRA 40 GBC spectrophotometer. DPPH scavenging activity was determined from the equation:

$$
\text { DPPH }(\%)=1-\frac{A_{\mathrm{x}}}{A_{0}} \times 100
$$

The same procedure was carried out in toluene, instead of oil, in order to measure $A_{0}$. The value $A$ was the absorbance 
Table 1. Total oil and fatty acid content in the cotyledons of Turkish hazel genotypes (\%)

\begin{tabular}{|c|c|c|c|c|c|c|c|c|c|c|}
\hline Compound/Genotype & & A8 & A9 & A11 & B6 & $\mathrm{B} 10$ & $\min$ & $\max$ & avg & SD \\
\hline oil yild (\%) & & 50.90 & 39.20 & 60.80 & 39.60 & 36.50 & 36.50 & 60.80 & 45.40 & 10.20 \\
\hline palmitic & C16:0 & 7.40 & 5.95 & 5.82 & 6.10 & 6.30 & 5.82 & 7.40 & 6.31 & 0.63 \\
\hline margaric & C17:0 & 0.44 & 0.04 & 0.06 & 0.07 & 0.04 & 0.04 & 0.44 & 0.13 & 0.17 \\
\hline stearic & C18:0 & 2.21 & 3.09 & 3.39 & 2.41 & 2.25 & 2.21 & 3.39 & 2.67 & 0.54 \\
\hline arachidic & C20:0 & 0.11 & 0.16 & 0.15 & 0.13 & 0.11 & 0.11 & 0.16 & 0.13 & 0.02 \\
\hline$\Sigma$ SAFAs & & 10.16 & 9.24 & 9.42 & 8.71 & 8.70 & 8.18 & 10.16 & 9.24 & 0.74 \\
\hline palmitoleic & C16:1E & 0.04 & 0.02 & 0.03 & 0.02 & 0.02 & 0.02 & 0.04 & 0.03 & 0.01 \\
\hline palmitoleic & C16:1Z & 0.46 & 0.24 & 0.26 & 0.26 & 0.32 & 0.24 & 0.46 & 0.31 & 0.09 \\
\hline cis-10-heptadecenoic acid & C17:1 & 0.82 & 0.06 & 0.09 & 0.08 & 0.07 & 0.06 & 0.82 & 0.22 & 0.33 \\
\hline elaidic & C18:1 & 0.41 & 0.03 & 0.33 & 0.24 & 0.067 & 0.03 & 0.41 & 0.21 & 0.17 \\
\hline oleic & C18:1 & 80.14 & 81.34 & 79.34 & 79.57 & 83.00 & 79.34 & 83.00 & 80.68 & 1.51 \\
\hline gadoleic & C20:1 & 80.14 & 81.34 & 79.34 & 79.57 & 83.00 & 79.34 & 83.00 & 80.68 & 1.51 \\
\hline$\Sigma$ MUFAs & & 82.03 & 81.88 & 80.22 & 80.34 & 83.62 & 80.22 & 83.62 & 81.62 & 1.40 \\
\hline linoleic & C18:2 & 8.81 & 8.78 & 10.20 & 10.81 & 7.52 & 7.52 & 10.81 & 9.22 & 1.30 \\
\hline linolenic & C18:3 & 0.09 & 0.07 & 0.11 & 0.09 & 0.09 & 0.07 & 0.11 & 0.09 & 0.01 \\
\hline$\Sigma$ PUFAs & & 8.90 & 8.85 & 10.31 & 10.90 & 7.61 & 7.61 & 10.90 & 9.31 & 1.30 \\
\hline$\Sigma$ PUFAs/ $\Sigma$ SAFAs/ & & 0.87 & 0.96 & 1.09 & 1.25 & 0.87 & 0.87 & 1.25 & 1.00 & 0.16 \\
\hline
\end{tabular}

SAFAs - saturated fatty acids (C16:0, C17:0, C18:0, C20:0); MUFAs - unsaturated fatty acids (C16:1, C17:1, C18:1, C20:1); PUFAs - polyunsaturated fatty acids (C18:2, C18:3).

Table 2. Sterol contents of five genotypes of Turkish hazelnut (mg/g oil)

\begin{tabular}{|c|c|c|c|c|c|c|c|c|c|}
\hline Compound/Genotype & RI & A8 & A9 & A11 & B6 & $\mathrm{B} 10$ & Mean & Mean (\%) & $\mathrm{Cv}(\%)$ \\
\hline cholesta-3,5-dien-7-on & 3227 & 0.11 & 0.15 & 0.13 & 0.10 & 0.20 & 0.14 & 2.55 & 29.77 \\
\hline campesterol & 3284 & 0.30 & 0.28 & 0.20 & 0.19 & 0.22 & 0.24 & 4.36 & 20.03 \\
\hline stigmasterol & 3314 & 0.08 & 0.10 & 0.12 & 0.07 & 0.11 & 0.10 & 1.80 & 22.78 \\
\hline n.i. $(M W=490)$ & 3352 & 0.21 & 0.15 & 0.16 & 0.13 & 0.14 & 0.16 & 2.90 & 19.96 \\
\hline$\beta$-sitosterol & 3377 & 3.93 & 4.25 & 3.18 & 2.96 & 3.57 & 3.58 & 65.09 & 14.74 \\
\hline n.i. $(M W=488)$ & 3382 & 0.08 & 0.07 & - & 0.06 & 0.09 & 0.06 & 1.09 & 58.81 \\
\hline fucosterol & 3395 & 0.73 & 0.71 & 0.60 & 0.45 & 0.49 & 0.60 & 10.91 & 21.60 \\
\hline gramisterol & 3415 & 0.03 & 0.03 & 0.02 & 0.03 & - & 0.02 & 0.36 & 57.04 \\
\hline (3 $\beta$ )-lanosta-8,24-dien-3-ol & 3432 & 0.05 & 0.04 & 0.02 & 0.04 & 0.13 & 0.06 & 1.09 & 74.94 \\
\hline cycloartenol acetate & 3435 & 0.12 & 0.09 & 0.04 & 0.06 & - & 0.06 & 1.09 & 74.02 \\
\hline (3 $\beta)$-cholest-5-ene-3,25-diol & 3453 & 0.18 & 0.17 & 0.19 & 0.14 & 0.22 & 0.18 & 3.27 & 16.41 \\
\hline n.i. $(M W=512)$ & 3476 & 0.02 & 0.02 & 0.02 & 0.02 & - & 0.02 & 0.36 & 59.60 \\
\hline$(9,19)$-ciclolanostan-3-ol & 3489 & 0.15 & 0.12 & 0.06 & 0.06 & 0.08 & 0.09 & 1.63 & 43.84 \\
\hline n.i. $(M W=500)$ & 3514 & 0.02 & 0.02 & 0.02 & 0.02 & - & 0.02 & 0.36 & 58.00 \\
\hline n.i. $(M W=498)$ & 3520 & 0.13 & 0.22 & 0.14 & 0.15 & 0.14 & 0.16 & 2.90 & 24.36 \\
\hline 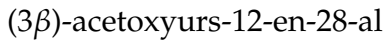 & 3630 & 0.02 & 0.08 & 0.01 & 0.02 & - & 0.02 & 0.36 & 143.45 \\
\hline Total & - & 6.16 & 6.50 & 5.10 & 4.50 & 5.39 & 5.50 & - & - \\
\hline
\end{tabular}

n.i. indicates that the compound is not identified. 
Table 3. Antioxidant activity of the Turkish hazelnut oils against DPPH radical

\begin{tabular}{lrr}
\hline & $\mathrm{EC}_{50}(\mathrm{~mL} / \mathrm{mL})$ & $\mathrm{EC}_{50}(\mathrm{mg} / \mathrm{mL})$ \\
\hline A8 & 0.1189 & 107.01 \\
A9 & 0.0867 & 78.03 \\
A11 & 0.0999 & 89.91 \\
B6 & 0.1228 & 110.52 \\
B10 & 0.0879 & 79.11 \\
BHT & $/$ & 1.10 \\
\hline
\end{tabular}

of the remaining DPPH after a reaction with the oil solution. Each sample was measured in four different dilutions and every measurement was performed in triplicate and subsequently averaged. The $\mathrm{EC}_{50}$ value for each oil sample was determined from the graph DPPH $(\%)=\mathrm{f}(\mathrm{c})$ constructed from four dilutions (concentrations). Butylated hydroxytoluene (BHT), a synthetic antioxidant, was used as reference.

\subsection{Statistical analysis}

Statistical analysis was performed using "Statistica 10" software (StatSoft. Inc., Tulsa, OK. USA).

\section{RESULTS AND DISCUSSION}

Fatty acid compositions of hazelnut oils are summarized in Table 1 . The analyses of the Turkish hazel established a high total oil content, which ranged from $36.50 \%$ to $60.80 \%$. The greatest amount of total oil was extracted from the A11 (60.80\%) and A8 (50.90\%) genotypes. The average oil content of our samples $(45.40 \%)$ was lower than the $56.2-56.4 \%$ and $64.48-71.92 \%$ previously reported for Serbian and Turkish cultivar, respectively (Erdogan and Aygun, 2005; Miletić et al., 2007).

Oleic (79.34-83.00\%) and linoleic acids (7.52-10.81\%) were the major unsaturated fatty acids found in oil seeds of Turkish hazel, and comprised nearly more than $90 \%$ of the fatty acid composition in all nuts. Palmitic acid was the main saturated fatty acid (5.82-7.40\%) followed by stearic acid $(2.21-3.39 \%)$. Other saturated fatty acids detected were margaric and arachidic acids, but only in very small quantities $(<0.5 \%)$. Saturated fatty acids comprised about $9.24 \%$ of the total in average.

In addition to fatty acid composition, their ratio is also important, in particular the ratio of monounsaturated and saturated, and polyunsaturated and saturated fatty acids (Table 1). Polyunsaturated fatty acids in the cotyledons participated by $7.61 \%$ to $10.90 \%$, and saturated fatty acids by $8.18 \%$ to $10.16 \%$. Ratio of polyunsaturated and saturated fatty acids in the samples was low and ranged from 0.87 to 1.24 . The monounsaturated fatty acid content in Turkish hazel kernel was about ten times higher than the content of polyunsaturated and saturated acids (Table 1). The high nutritional value of Turkish hazel was partly due to the high ratio of monounsaturated and saturated fatty acids. Unsaturated fatty acids favorably affect blood cholesterol, regulate blood pressure, and enable the intake of Vitamin E (Alasalvar et al., 2003). The fatty acid profiles of our samples C. colurna were similar to literature data for C. colurna from Turkey (Erdogan and Aygun, 2005). The most common phytosterols, namely, $\beta$-sitosterol, campesterol, and fucosterol, were found in Turkish hazelnut oil. Among them, $\beta$-sitosterol comprised in average $65 \%(2.96-4.25 \mathrm{mg} / \mathrm{g})$ of the total phytosterlols followed by fucosterol $(0.45-0.73 \mathrm{mg}$ $\left.\mathrm{g}^{-1}\right)$ and campesterol $(0.19-0.30 \mathrm{mg} / \mathrm{g}) . \beta$-sitosterol contents found in this study were three to four times higher than those reported in the oils extracted from different $C$. avelana cultivars (Alasalvar et al., 2009). Significant content of phytosterols is important knowing their role in reducing total and LDL cholesterol and decreasing the risk of certain forms of cancer (Alasalvar et al., 2003; Moreau et al., 2002). Sterol content of Turkish hazelnut are presented in Table 2.

The DPPH radical scavenging assay is commonly employed in evaluating the ability of antioxidants to scavenge free radicals. The decrease in absorbance at $515 \mathrm{~nm}$ is used as a measure of the scavenging effect of a particular extract for DPPH radicals. The DPPH values for the five Turkish hazel oil against the control (BHT) expressed as $\mathrm{EC}_{50}$ are shown in Table 3. The antioxidant activity of Turkish hazelnut oil was tested against DPPH radical at $0.1,1.0,10$, and $100 \mathrm{mg} / \mathrm{mL}$ concentrations The highest antioxidant activity was displayed by the oil from genotype $\mathrm{A} 9\left(\mathrm{EC}_{50}=78.03 \mathrm{mg} / \mathrm{mL}\right)$. The synthetic antioxidant $\mathrm{BHT}_{\mathrm{Had}} \mathrm{EC}_{50}$ of $1.10 \mathrm{mg} / \mathrm{mL}$ under the same conditions. The results showed that all of the oils exerted a similar scavenging effect towards DPPH.

\section{CONCLUSION}

In this work, composition of fatty acids and phytosterols in the oil obtained from cotyledons of Turkish hazel genotypes (C. colurna L.) was determined. High oil content was established, ranging from $36.50 \%$ to $60.80 \%$. The predominant fatty acid in the analyzed Turkish hazel kernels was monounsaturated oleic acid, contributing by $79.34 \%$ to $83.00 \%$. Among polyunsaturated acids, linoleic was predominant with content ranged from $7.52 \%$ to $10.81 \%$. Phytosterol content analysis revealed $\beta$-sitosterol as dominant, with concentrations ranging from $2.96 \%$ to $4.25 \%$. High content of monounsaturated fatty acids (oleic) favorable ratios of mono- and polyunsaturated to saturated fatty acids. High content of phytosterols recommend the oil of Turkish hazel kernels as high quality nutritional and medicinal food.

\section{ACKNOWLEDGMENTS}

The authors acknowledge their gratitude to the Ministry of Education and Science of the Republic of Serbia (Grant no. 172053) for financial support.

\section{REFERENCES}

AACC (1991). Crude fat in wheat, corn, and soy flour, feeds, and cooked feeds (Method 30-25). American Association of Cereal Chemists Approved Methods, 8th edn. edn, St. Paul, MN.

Alasalvar, C., Amaral, J. S., Satır, G. and Shahidi, F. (2009). Lipid characteristics and essential minerals of native Turkish hazelnut varieties (Corylus avellana L.), Food Chemistry 113(4): 919-925.

Alasalvar, C., Amaral, J. S. and Shahidi, F. (2006). Functional lipid characteristics of Turkish tombul hazelnut (Corylus avellana L.), Journal of Agricultural and Food Chemistry 54(26): 10177-10183.

Alasalvar, C., Shahidi, F., Liyanapathirana, C. M. and Ohshima, T. (2003). Turkish tombul hazelnut (Corylus avellana L.). 1. Compositional characteristics, Journal of Agricultural and Food Chemistry 51(13): 3790-3796.

Amaral, J. S., Cunha, S. C., Santos, A., Alves, M. R., Seabra, R. M. and Oliveira, B. P. P. (2006). Influence of cultivar and environmental conditions on the triacylglycerol profile of hazelnut (Corylus avellana L.), Journal of Agricultural and Food Chemistry 54(2): 449-456. 
Crews, C., Hough, P., Godward, J., Brereton, P., Lees, M., Guiet, S. and Winkelmann, W. (2005). Study of the main constituents of some authentic hazelnut oils, Journal of Agricultural and Food Chemistry 53(12): 4843-4852.

Cristofori, V., Ferramondo, S., Bertazza, G. and Bignami, C. (2008). Nut and kernel traits and chemical composition of hazelnut (Corylus avellana L.) cultivars, Journal of the Science of Food and Agriculture 88(6): 1091-1098.

Erdogan, V. and Aygun, A. (2005). Fatty acid composition and physical properties of Turkish tree hazel nuts, Chemistry of Natural Compounds 41(4): 378-381.

IUPAC (1987). Standard Methods for the Analysis of Oils, Fats and Derivatives, 7th edn, Oxford, Blackwell, chapter Preparation of fatty acid methyl ester, p. Method 2.301.

Miletić, R., Mitrović, M., Rakicević, M., Blagojević, M. and Karaklajić-Stajić, a. (2007). The study of populations of hazelnut C. avellana L. and Turkish hazelnut C. colurna $\mathrm{L}$. and their selection, Genetika 39(1): 13-22.

Moreau, R. A., Whitaker, B. D. and Hicks, K. B. (2002). Phytosterols, phytostanols, and their conjugates in foods: structural diversity, quantitative analysis, and health-promoting uses, Progress in Lipid Research 41(6): 457-500.

Ninić-Todorović, J. (1990). A study of dominant factors and determination of optimum technological methods for producing high quality nursery plants of Turkish filbert (Corylus colurna L.), Ph.D. Thesis, Faculty of Forestry, University of Belgrade.

Oliveira, I., Sousa, A., Morais, J. S., Ferreira, I. C., Bento, A., Estevinho, L. and Pereira, J. A. (2008). Chemical composition, and antioxidant and antimicrobial activities of three hazelnut (Corylus avellana L.) cultivars, Food and Chemical Toxicology 46(5): 1801-1807.

Ozdemir, F. and Akinci, I. (2004). Physical and nutritional properties of four major commercial Turkish hazelnut varieties, Journal of Food Engineering 63(3): 341-347.

Parcerisa, J., Richardson, D. G., Rafecas, M., Codony, R. and Boatella, J. (1998). Fatty acid, tocopherol and sterol content of some hazelnut varieties (Corylus avellana L.) harvested in Oregon (USA), Journal of Chromatography A 805(1-2): 259268.

Ramadan, M. F. and Moersel, J.-T. (2006). Screening of the antiradical action of vegetable oils, Journal of Food Composition and Analysis 19(8): 838-842.

Seyhan, F., Ozay, G., Saklar, S., Ertas, E., Satir, G. and Alasalvar, C. (2007). Chemical changes of three native Turkish hazelnut varieties (Corylus avellana L.) during fruit development, Food Chemistry 105(2): 590-596.

Thompson, M., Lagerstedt, H. and Mehlenbacher, S. (1996). Fruit Breeding, John Wiley \& Sons, New York, chapter Nuts. Hazelnuts, pp. 125-184.

Xu, Y. and Hanna, M. (2009). Synthesis and characterization of hazelnut oil-based biodiesel, Industrial Crops and Products 29(2-3): 473-479.

Xu, Y. and Hanna, M. (2010). Evaluation of Nebraska hybrid hazelnuts: Nut/kernel characteristics, kernel proximate composition, and oil and protein properties, Industrial Crops and Products 31(1): 84-91. 